\title{
SOCRATIC QUESTIONING TO PROMOTE EFL STUDENTS' CRITICAL THINKING IN A LANGUAGE LEARNING
}

\author{
I Putu Andre Suhardiana \\ Institut Hindu Dharma Negeri Denpasar \\ putuandresuhardiana@gmail.com
}

\begin{abstract}
This paper addressed the use of the Socratic Questioning method as an attempt to promote EFL students' critical thinking in language learning. It is ordinarily understood that the process of learning the language tends to focus more on how to answer questions rather than how to ask productive, systematic, and directed questions. Questioning as a means to fulfil curiosity is a driving factor for critical thinking activities. Questioning is able to direct the task and define the problem so that it will spur and trigger students' critical thinking. The use of Socratic Questioning and critical thinking methods embraces and encourages the analysis of Bloom's taxonomy integrally since Bloom's critical thinking is assigned as one of the highest levels of thinking in cognitive domains. Socratic Questioning, critical thinking, and Bloom's taxonomy are lines that must be passed in a language learning process in order to achieve the quality of skills which surely depends on the quality of thinking.
\end{abstract}

Keywords: Socratic Questioning, Critical Thinking, Language Learning

\section{INTRODUCTION}

Education is an effort made to develop the abilities and personality of individuals through certain processes or activities (teaching, guidance, or training) as well as the interaction of individuals with their environment to achieve full humanity (Sary, 2015: 3-5). Without education, it is impossible for a group of people living to develop their aspirations to progress, prosper, and be happy according to their concept of life (Fuad, 2008: 2). The government through Regulation No. 19, 2005 stated that language education points to equip graduates to be able to communicate using language as a tool of communication on the international scene. In short, the government has given prominent consideration for teaching English with the target of communication skills. At the university level, English is a compulsory subject. Government Regulation No. 19 of 2005 Article 9 paragraph (2) asserts that the curriculum of higher education unit level must involve courses in religious education, citizenship education, Indonesian, and English. The purpose of learning English is as a means of developing students' language skills competencies listening, speaking, reading, and writing. Each college develops its 
curriculum by referring to the National Education Standards (Law No. 20/2003 on the National Education System).

The rational reasons for questioning and critical thinking could be directed to Socrates (469399 BCE), 2,500 years ago (Abelman \& Atkin, 2011, p. 3). This famous scholar advised his students to investigate and analyse critically both common-sense beliefs and discovered facts. When lecturers help students not to get anything for awarded, they are then utilizing the Socratic method in their teaching by setting the roots of significant insight into students' perceptions. Passionate proponents for this process claim that it displays a great connection with the way of thinking required and that it is well in comprehensive classrooms. It makes the Socratic method considered to be at the core of proper pedagogy. In fact, no firm explanation of the Socratic way has been given so far since it is flexible. Any lecturer could use it for a demanding pedagogical goal. Here are several publicly distributed definitions of the Socratic method:

a) The Socratic method works with the presumption that the purpose of education is to bring the truth out of the student rather than "fill an empty vessel." In practice, it is a set of controlled questions identified as the rational process of inquiry (Soccio, 2015 , p. 10, italics in original)

b) It has come to expect any pedagogy led through question and answer, as recognized from pedagogy carried in lecture form (Scott, 2012, p. 1)

c) Any philosophical or pedagogical method seeks truth through scientific analysis (Spencer \& MillsonMartula, 2009, p. 39).

According to Reich (2003), who adopted the Socratic method, the lecturer is not the purveyor of information, that is, the one who tells facts and truths to passive learners after years of study. The lecturer is not "the master on the scene," but she or he, similar to the students, is another member in the construction of information. Therefore, lecturers are responsible for leading students to a "deeper and refined thought of the ideas of the text, regard for varying points of view, and adherence to and respect for the learning process" (Tredway, 1995, p. 28). What is fascinating in the Socratic process is not particularly its aim to question but also its influential function to support students differentiate objective thoughts from extravagant or ill-formed ones. Copeland (2005) asserted that it is imperative for the lecturer to illuminate that persistent questioning in the class is not intended to form an atmosphere of discrimination, but rather to encourage students to explore their views and beliefs.

Teaching within the Socratic scheme turns from the expository or formal lecture-style direction in three ways. First, the Socratic method does 
not require the lecturer bringing a group of proficient information to impart to students. In (Plato's) Theaetus, Socrates examines the lecturer's performance to assists the student through the process, but it is the student who produce the knowledge. Second, the learning that takes place through the Socratic method comprises the dropping of fake information, rather than adding the right information. Third, there are no 'right' answers to Socratic questions. (Spencer \& MillsonMartula, 2009, p. 40). Socrates applied this system to guide students to the truth. He made his purpose through regular and precise questioning, in the way of which he addressed his opponents to look at their needs and weaknesses. He was unusually intent on forming logical thinking based on thought. For the Socratic method to be successful as an educational method, lecturers require to create what is named the Socratic study. Since the lecturer's position is essentially as a creator and facilitator, the final success of the class is likely on the performance of the students. "Whatever text is taken, students are demanded to come to class equipped to jointly review the text" (Johnson, 2003, p. 33) and get the most out of it. The goal of the Socratic class is to promote students to think for themselves and appreciate their own questions. The class trains their reasoning and thinking skills and involves them in severe mental exercise with no resistance from the lecturer.
In the past two decades, the conversation of critical thinking as an educational goal has become increasingly serious. In general, critical thinking is characterized by the capability to think rightly, systematically, and logically in understanding concepts or theories to take action and solve problems based on the mechanism of conceptual analysis and argumentation (Pithers \& Soden, 2001). Various definitions of critical thinking are proposed based on a variety of constructs and progress. Dewey, for example, characterizes critical thinking as an active, consistent, and careful activity in considering a related belief and conclusion (in Black, 2008). Meanwhile, Ennis (1996) relates it to reflective thinking that focuses on establishing beliefs and actions. A more practical definition offered by Ruggieo is the process of testing useful arguments. In other words, this process involves the main skills in doing academic assignments such as processing, concluding, and synthesizing information, evaluating skills, and creating (Errihani, 2012). Critical thinking in the context of foreign language education involves language activities that encourage students to interpret, collaborate in the practice of using foreign languages, use conventions in the ability to write, apply cultural knowledge, solve problems regarding the topic concerned, reflect language usage, and create discourse. This view is summarized by Kern (in Hayat \& Yusuf, 2010) to be an approach to literacy-based teaching 
and learning processes involving response, revision, and reflection.

The concept of critical thinking is classified into two views, specific and generalist. The specific concept considers critical thinking to be context-bound, such as basic knowledge and certain disciplines. On the other hand, generalist concepts assume that critical thinking applies across contexts and disciplines (Emilia, 2010). It is this generalist concept which later becomes the foundation in the integration of critical thinking and foreign language discourse since the dynamics appear in cross contexts including linguistic contexts. This is supported by the empirical findings of Indah (2012) which states that no significant differences were found in the expression of students' critical thinking on reflective writing in English and Indonesian. The integration of critical thinking and language learning in Indonesia still requires further exploration in view of the uniqueness of the linguistic context related to multilingual and multicultural conditions. A case study that analyses written Englishlanguage students shows that the problem arises is not critical thinking skills but rather related factors such as language proficiency and material understanding (Samanhudi \& Sampurna, 2010). Therefore, lecturers are recommended to adopt English language teaching materials to promote critical thinking skills (Sepriani, 2010) as well as applying various methods to support the development of students' skills in critical thinking (Yumarnamto \& Widiyanto, 2005). However, cultural constraints in efforts to develop critical thinking skills are indeed still an inevitable factor (Kameo, 2007).

Questions play a significant role in formulating a productive discussion atmosphere and that leads to critical thinking as proposed by Campbell (2004: 13) which states that questions that stimulate discussion should be thoughtful and not easily answered in a few words. Therefore, it is very important for lecturers to pass accessible and engaging questions (open-ended and interesting questions) so as to be able to inspire and provide a new possibility in learning. In general, answering questions are more familiar than asking questions in the learning process. In fact, there is almost no questioning among students at the time of the lecture. This phenomenon is not surprising because normally there is only a short time allocated for question and answer session. It is usually not more than 10 minutes, sometimes even not be given at all. Such kind of portrait of learning is not entirely the fault of students who are often considered to be less brave, less confident, and less creative. Nevertheless, if we observe deeply, how often we ask questions to students? It is either at the beginning, middle, or end of the lecture, and whether the question is able to encourage them to think critically or the questions we ask are only at the remembering level, the lowest level in the new version of Bloom's taxonomy (Anderson \& 
Krathwohl, 2001: 67-68) so that it is unable to stimulate students to think critically. There are academic issues that are considerably mattering regarding this learning both from the side of the learning community and from the side of the teaching staff. The problem is how to optimize questioning proportionally in the language learning process.

\section{DISCUSSION}

\subsection{Current Issues in Language Learning}

Johnson (2001: 41-44) outlines two views associated with language learning: behaviorism and rationalism. The initiators of the flow of behaviorism are Ivan Pavlov, John Watson, Edward Thorndike, and Burrhus Skinner. In their view, language learning is greatly influenced by three factors: 1) Conditioning: language learning is seen as a process of conditioning the relationship between stimulus and response. 2) Habit formation: language learning is seen as a process of habituating language behavior in stages starting from simple to complex behaviors. 3) The importance of environment: there are two prominent parts of language learning: organisms and environment. Organisms are people/animals as language learners, while the environment is anything outside of the learner (events, situations, other people besides learners such as teachers or parents). In the view of behaviorism, the environment is crucial in the process of language learning, even organisms are considered insignificant.

This behaviorism flow received strong resistance from the flow of rationalism, particularly towards the third idea concerning the quality of the environment. The pioneers of this flow are Chomsky (1959), Lyons (1970), Cook and Newson (1995). The view of rationalism assumes that what is most decisive is not the environment but the organism. They believe that the mind and everything linked to the mind such as consciousness and thoughts are a very decisive part of language learning rather than just human behavior. From the brief description above, it is clear that the flow that focuses more on optimizing thinking is the flow of rationalism so that the flow can definitely support the critical thinking in language learning.

\subsection{Bloom's Taxonomy of Learning Domains}

Thinking activities cannot be separated from the idea of Benjamin Samuel Bloom, better known as Bloom's taxonomy, a very phenomenal, monumental, and influential idea among academics and practitioners of education. Bloom considers that learning, teaching, identifying educational goals, and thinking are complicated concepts interwoven in an intricate web. For Bloom learning, the purpose of education and thinking are concepts which closely correlated to each other in a fairly complex structure. Such problems also according to Houghton 
(2004) are often faced by educators "where do we begin in seeking to improve human thinking?" Since thinking can be the improvement of student learning.

Bloom composes taxonomy (classification) in relation to educational goals in three domains: cognitive, affective, and psychomotor. However, Bloom's taxonomy which is discussed here is taxonomy on the cognitive domain level. Since the 1990s, Bloom's taxonomy has undergone a change known as Revised Bloom's Taxonomy (RBT). This RBT was initiated by Bloom's student, Lorin Anderson. The fundamental difference between the original cognitive taxonomy (old version) and the RBT (new version) is located in the number of dimensions. The old versions have only one dimension (knowledge, comprehension, application, analysis, synthesis, and evaluation), while the new version has two dimensions: the first dimension is the knowledge dimension that identifies the type of knowledge that must be learned (knowledge to be learned); the second dimension is the dimension of the cognitive process that identifies the process used for learning (process used to learn). What demands to be observed from the RBT above is the composition of the division of knowledge dimensions consisting of four levels (factual, conceptual, procedural, and metacognitive), and composition of dimensions of cognitive process division consisting of six levels (remembering, understanding, applying, analyzing, evaluating, and creating). In underlying this RBT, the ability of students must be measurable so that verbs need to be constructed that can measure intellectual behavior in learning.

\subsection{Students' Critical Thinking Ability}

The pedagogical concept of critical thinking is rooted in the Socratic notion of "deep questioning", which manifests in almost all the definitions of critical thinking. Norris and Ennis (1989) define critical thinking as "reasonable reflective thinking" focused on deciding what to believe or do through cognitive skills of analyzing, inferring, interpreting, and evaluating (p. 3). Thus, having qualities of 'explanation' and 'selfregulation', critical thinking allows individuals to strengthen their own powers of ratiocination and lateral thinking skills. Lipman (1991) defines it as "healthy scepticism". Lewis \& Smith (2001) call it "higher order thinking", while Jacobson and Ignacio (1997) and Jacobson (1998) consider it to be "conscious use of learning strategies", which involves engagement in a task and increases the awareness of the context. According to Jacobson (1998), critical thinking entails self-improvement, which corresponds with the findings of Varadani \& Mehrali's (2013) study in that there is a significant relationship between critical thinking and self-efficacy and levels of proficiency (p. 2355). Halpern (1996) 
considers critical thinking as "goaldirected" and "evaluation-oriented". A similar definition is provided in Whitmore's (1998) analysis which looks at critical thinking as an ability to identify central issues, evaluate conflicting claims based on evidence on authority, and interpret whether conclusions are warranted or not accordingly (pp. 266-273). Siegel (1988) highlights two elements of critical thinking that are relevant to educational contexts, namely (a) the ability to assess reasons adequately, and (b) the critical attitude reflected in the willingness, desire and disposition to support one's beliefs and actions by reasons (p. 23). Lakshmi (2012) is of the view that, in the context of classroom teaching, any conscious thinking that is goaloriented is critical thinking (p. 113). Put precisely, all the thinking abilities, as reflected in the above definitions, can be broadly put under the three sub-skills of critical thinking, namely creative thinking, logical reasoning, and problem solving.

\subsubsection{Theoretical Foundations of Critical Thinking}

Critical thinking has strong theoretical foundations and scaffoldings to base on and erect as a fruitful pedagogical practice in ESL / EFL classrooms. Bloom (1981) developed a system, popularly known as Bloom's Taxonomy, of classifying levels of thinking in the cognitive domain involved in the learning process. The thinking in cognitive domain builds on the simple factual knowledge at the lowest level whereas evaluation at the highest level. Piaget \& Inhelder's (1970, cited in Vezzosi, n. d., p. 7), consider thinking skills as maturational, which bring individuals to consider their lives from the point of view(s) of others in order to think and evaluate their own thinking. Vygotsky's model (2000, cited in Vezzosi, n. d., p. 7) proposes that thinking and its constructs are products of social and interpersonal activity, which eventually get internalized as individual knowledge. Benesch's (1993) model emphasizes critical thinking as a social practice and examines it as a quest for social, political and historical roots of traditional knowledge and also as an orientation to transform learning and the society. With a section on the theoretical foundations of critical thinking, what follows next is a discussion on why and how pictorial presentations of cartoons and caricatures can be effective means of facilitating orientation of critical thinking in ESL/EFL classrooms.

\subsection{Socratic Method}

The Socratic Method begins with Socrates, an Athenian philosopher who lived around 470 B.C. Socrates was born the son of a sculptor and was raised as a sculptor himself. Nevertheless, he recognized that he was the sculpting of (Knezic, et al, 2010). In those who acquired from him, he encouraged to love, loyalty and a feeling of affection. Describing him, Xenophon, one of his 
students, wrote: “...Socrates presented himself an illustration to those who joined with him as a man of noble and great character" (Knezic, et al, 2010). Socrates reached the character for fastening others in conversations whose intention was to represent broad concepts such as power, grace, truth, strength, and friendship by considering their uncertainties and complexities. All this was highlighted in discussions written next by his student Plato. Thus, Plato's Dialogues are an excellent source available for Socrates' method and philosophy (Knox, 1998). His position in those discussions was that of a student, driving his respondents to behave in the role of teacher. definition of the Socratic method gives Nicholas Schiller (Schiller, 2008), stating Copleston's History of philosophy in his paper. There the method is defined as follows: "...Therefore, he asked questions, assigning the other man do most of the talking, but keeping the course of the discussion under his direction, and so would display the inability of the intended definition of courage. The other would come back on a new or modified definition, and so the process would go on, with or without ultimate success" (Schiller, 2008, p. 3).

The pattern on the side" vs "The master on the scene" The discussion of the Socratic Method is found in Chang, Lin, Chan's work (1998). In their work, the authors emphasized that "points in the Socratic method when it is utilized for learning. Firstly, its learning goal is "inquiry". Its objective is not to fully engage students' primary reasons but to partially modify their primary reasons. Secondly, its method is a discussion between student and teacher. The role of a teacher is to ask the questions and students' to build their knowledge in answering the questions. Thirdly, between teacher and students, it is also inductive. The teacher continuously guides the students to reason inaccurately then practices the counterexample to explain the problem. The principal characteristic of the Socratic method is that it is not "teaching" in the common sense of the word. The teacher is an observer, an assistant, model but purveyor of information. Lectures with "undeniable" facts and truths and rote memorization or, in other words, "guiding the students" are renewed with and teachers where both are responsible for driving the conversation forward through questioning. The Socratic method has five steps: 1. Wonder (posing questions such as: what is courage, what is virtue, etc.); 2 . Hypothesis (an answer to the wonder, one gives his opinion or claim about the question which becomes a hypothesis of the dialogue); 3. Elenchus, refutation, and cross-examination (the core of Socratic practice; the hypothesis is called into question and the counterexample is given to prove or disapprove the hypothesis; 4 . Acceptance/rejection of the hypothesis (participants accept or reject the counterexample); 5. Action 
(acting on the findings of the inquiry) (Boghossian, 2012).

Socrates expected to form each person being a leader and being a state. We can learn from him that only the along with self-developed attacks of persuasion, any other authority. This may critical thinking as Socrates' students, through proper and renewed questioning, to organize their own thoughts (Douglas, 2014). Using the Socratic method in teaching, providing students questions and not answers, reasoning and the of their current knowledge and experience. be directly taught, by the Socratic method it can be occupied and cultivated and students are encouraged to develop this skill (Lam, 2011).

\subsubsection{Classic Socratic method}

The Socratic method can be classified into two foremost kinds. Maxwell (2013) breaks it into a classic and modern version of the Method. In his paper Introduction to a Socratic method and its impact on he reveals that the term classic refers to the early Socrates' conversations and some other conversations of Plato. „In these conversations, Socrates claims to have no information of most basic principles such as truth, righteousness, friendship or power" (Maxwell, 2013). Thus, the goal of these conversations is taking only short answers that discuss very specific details. The purpose is to obtain sufficient knowledge of fundamental beliefs instead of going to more difficult and complex topics.
This style serves essentially in determining the terms and topics to be addressed. There is no sense in questioning justice if one doesn't know what is justice. The goal of the first style of the Socratic method is that equips people to create and to promote themselves through improved understanding. This phase deconstructs people's prior knowledge and helps them know what they do not know.

\subsubsection{Modern Socratic Method}

This kind of Socratic method is not defined modern since it has been discovered lately but because it is generally used in modern times. It starts in Plato dialogues and is distinct from the classic Socratic method in that it affects a person step by step and information is gained by more and more questions. If the classic style is just describing or classifying various topics, the Modern goes deeper, specific knowledge of those topics. People are questioning their own beliefs and thus improving their critical thinking. The Modern Socratic method generates a condition in which the students are not ignorant and in which they know the answer. One of the advantages of the Socratic method is that it renders the student and the teacher into an affection which cannot be achieved by lecturing as they both become active participants in the teaching and learning process (Knox, 1998). The emphasis is on asking well-formed questions and advancing the study, not on getting absolute answers. 


\subsubsection{Socratic Dialogue}

The main point through which Socrates teachings are us are the conversations conveyed in the works of his first students such as Plato. As discussed above, Plato's Conversations available for Socrates' method and philosophy. Socrates' principal thought of starting the conversations and dialogues with ordinary people of Athens was, as he used to describe, doing a midwifery job. "Socrates declared that just like his mother he was practicing midwifery. Only his mother helped pregnant women deliver babies, whereas he encouraged his followers to deliver knowledge. so mostly by questioning: first driving his collocutors into self-contradiction (elenchus) and thus freeing them of their false preconceptions and then treating them to deliver the right information" (Knezic, et.al. 2010). So, questioning is to implement several types to a discussion. One of the ways is in the form of elenchus, a cross-examination in which questions are asked regarding beliefs in such a way as to expose contradictions. According to Knezic et al. (2010), the group in the dialogue may consist of six to twelve participants. The role of the facilitator is not necessary in order to guarantee the participants' deployment of their own abilities and ideas. He/she may just hold the focus on the current question. It is important for him/assist participants to reach to make sure important issues are dealt with. To keep the "togetherness" of the group is also extremely necessary. Observing participants while in the dialogue is also worth being capable of. Some principles and methods for this could be to raise complex questions, to present counterexample when they make contradictions with their statements, to ask them to make predictions about the ultimate purpose, etc. (Chang et al. 1998.) The critical task in the Socratic dialogue is "how to ask". Questions should be more complicated, raising students' thinking and evaluating their ideas (Chan et al. 1998). With his dialogues, Socrates made a transition to a human-centered education model from a strong emphasis on enormous learning potential and creativity of humankind. Socrates himself did not write. His ideas are written by his contemporaries Plato, Xenophon, and Aristophanes. Plato's Socratic dialogs are a body of literature that record a Socrates and people who professed to have knowledge on a certain subject (Schiller, 2008).

The idea (of having a debate/argument) is not to "win" and to make others feel ashamed. The way we see it, the goal of having a debate/dialogue is to obtain out the truth, or very least, our mind. When performed rightly by an excellent professor, the Socratic Method can really create a lively, engaging, and intellectual classroom environment. Socratic Seminars (also known as a Socratic Circle) are exploratory intellectual conversations focused on a planned in such a way to match the Socrates instruction-throughquestioning method (Chorzempa and 
Lapidus, 2009). Socratic for its embodiment of Socrates' belief in the power of asking questions, prize inquiry over information and discussion over the debate. It is a pedagogical approach based on trying to get information in a text. Its systematic method is used to analyze a text through questions and answers. The purpose of a Socratic seminar is for students to encourage one another to understand the ideas, issues, and values reflected in a specific text. The seminar typically includes the following elements: a passage of text that students must read beforehand and two concentric circles of students: an outer circle and an inner circle. So, preparing for the activity is necessary. Teachers, assuming that students came prepared to the class, promote the process by first introducing the text to the students and then joining them in their preparation for the Socratic seminar (Chorzempa and Lapidus, 2009). After they read the text repeatedly (be more than once), they are asked to perform their questions. The inner circle focuses on exploring and analyzing the text through the act of questioning and answering. During this phase, the outer circle remains silent. Students in the outer circle are much like scientific observers watching and listening to the conversation of the inner circle. When the finished talking, circle provides feedback on the dialogue that took place, only during the consultation. This process alternates with the inner circle students going to the outer circle for the next meeting and vice versa. The length of this process varies depending on the text used for the discussion. The teacher may choose to alternate groups within one meeting, or they may alternate at each separate meeting. between this activity and the most typical classroom activities role of the teacher. In Socratic Circles, the students start the discussion and questioning. The purpose is to assure the discussion advances regardless of the particular direction the discussion takes. Socratic seminar often begins with the discussion leader, a student or the teacher, asking an open-ended question. A typical Socratic seminar opening prompt is: What do you think this text means? Students may take a few minutes to warm-up. organize a Socratic seminar like a fishbowl, (a method that helps students practice being contributors and listeners in a discussion), with some students participating in the discussion and the rest of the class having specific jobs as observers. It is by this that the Circle gives an environment of an intellectual meeting, assistance, and communication where students discover the distinction between dialogue and debate. Providing the process of effective learning and cooperation, Socratic seminars also help develop self-esteem and critical thinking. to feelings of competencethe ability to independently construct meaning and arrive at thoughtful ideas. When students make decisions, solve problems, give their own sense of significance. 


\subsubsection{Socratic Questioning Method}

Asking questions, according to Campbell (2004: 44), became a tradition among philosophers, even long before the time of Socrates. The questioning process is deemed to be a very common teaching practice. Frequently asked questions in the class vary according to the thinking capacity of the students. In line with such fact, Ramsey et al. (1990) also placed questioning as an effective teaching method.

\subsubsection{Questioning}

According to Webster's Encyclopedic Unabridged Dictionary of the English Language (1989: 1179), questioning is categorized into two types of words: adjectives and nouns. Questioning as an adjective has two meanings: 1) indicating or implying a question, 2) characterized by or indicating intellectual curiosity; inquiry, e.g. a questioning tone in the voice. As a noun, questioning is defined as an inquiry or interrogation. From the perspective of lexical meanings above, both the meaning of questioning drawn from adjectives and nouns categories, all indicate conditions that allow for a systematic and directed dialogue process to obtain the knowledge to be known by using intellectual capacity.

In the context of critical thinking in learning, the questioning role is moderately significant in promoting the quality of thinking. This is clearly expressed in the article published in "The Critical Thinking Community-Foundation of Critical Thinking" entitled The Role of
Socratic Questioning in Thinking, Teaching, \& Learning. The article explained that the quality of the questions posed by students determine the quality of thinking. Thus, questioning and critical thinking is a package that cannot be separated from each other, and this is clear in the critical thinking handbook that questioning is one part of cognitive strategies of 35 dimensions of critical thinking.

Questioning in the context of critical thinking is a questioning activity to develop cognitive capacity, and this sort of questioning has its own characteristics. There are at least three characteristics that can be represented, such as 1) questioning that raises further questions, not questions that expect thoughtstopping answers, 2) questioning that is able to encourage deep thinking, underneath the surface of things, and 3) questioning that is able to stimulate discussion deeply, and be able to be thought-provoking, not questioning that can be answered easily in just a few words.

The first two characteristics are drawn from the article of 'The Role of Socratic Questioning in Thinking, Teaching, \& Learning' and the last characteristic derived from Campbell (2004: 13) have a consistent substance, namely that questioning must develop productively, systematically, deeply, and directed.

\subsubsection{The Principles of Socratic Questioning}

Based on the aspects included in the article of 'The Role of Socratic 
Questioning in Thinking, Teaching \& Learning', that there is a specific correlation between critical thinking and Socratic questioning since both have the identical ultimate goal. Critical thinking provides a comprehensive view of how the mind functions (in finding meaning and truth), while Socratic questioning utilizes that view to form questions that are essential in the search for meaning and truth. Furthermore, from the article, the following will discuss major ideas respecting the principles of Socratic questioning, as well as how to prepare discussions/dialogues using the Socratic questioning method. There are a set of principles that can support to lead to Socratic dialogue. This series of principles apply directive sentences that can be performed by lecturers during the learning process. In Socratic dialogue, lecturers must be able to:

a) Respond to answers with further questions (which can enable students to develop their thoughts thoroughly and deeply).

b) Understand why the rationale is conveyed or understood and what the implications are through further questions.

c) Deliver a firm statement as a connection point for further thinking.

d) Deliver thoughts in the interest of developing further discussions.

e) Realize that every thought will be intact if the thoughts are interrelated with each other. f) Be aware that all questions must underlie the previous question and all thoughts must underlie the previous thoughts.

This ability should be possessed by a lecturer as a basis for reviving the Socratic dialogue. Moreover, lecturers who are involved in the Socratic dialogue must ask questions systematically on the basis of assumptions contained in the following elements of thought:

a. Be aware that thinking must reflect an agenda. We cannot understand the thoughts in their entirety until we understand the agenda first.

b. Be aware that thinking must be based on clear information. We cannot understand the whole thought until we understand the background of the information that supports it.

c. Realize that thinking requires drawing conclusions and giving meaning. We cannot understand full thinking until we understand the conclusions taken.

d. Be aware that thinking must be based on a clear concept. We cannot understand full thinking until we understand the concept used.

e. Be aware that thinking must be based on other thoughts (which must be taken for granted). We cannot understand our thoughts as a whole until we understand 
what thoughts have taken for granted.

f. Realize that thinking must have direction, implications, and consequences. It is not enough to just rely on assumptions. We cannot fully understand thoughts until we understand a thought unless we know the implications and consequences that work with it.

g. Be aware that engraving must be in a clear perspective. We cannot understand full thinking until we understand the point of view of the terms of reference used.

h. Realize that thinking takes into account of the question. We cannot understand our thoughts in their entirety until we understand the questions they ask.

The whole principles above require adequate conceptual skills and that will never be achieved if it is not well prepared and begins seriously as the actualization of academics.

\subsubsection{Questioning Construction in Socratic Dialogue}

To compile questioning in the Socratic dialog, first determine the important questions to discuss with the approach to developing the previous question. The previous question is a question that has been predicted by other questions. For example, to answer the question "What is multi-culturalism?" Students must first answer the question "What is culture?" And to answer the question "What is culture?" Students must first answer the question "What is the basis of culture?" And so on can be done by doing such a procedure. By using this questioning model, the academic atmosphere of the class grows more conducive. In addition, students' attention to the topic of lectures is increasingly focused.

\subsubsection{Socrates and Life-Long Learning \\ Concerning the story of} Socrates, if anything can be designated as Socrates philosophy that should be, by no means, his force for constant learning and education. Socrates insisted that human is the only incomplete beings in the universe and that they have a trend as well as a strength to extend into maturity (Demirci, 2012). Lifelong learning encourages humans to attain a level of completeness and selffulfillment. In their paper, The Determinants of Lifelong Learning (2016) Sinanovic and Becirovic, based on Delors' four pillars of education for the future, establish lifelong learning as "is flexible and at different places". The definition simply fits in the Socratic method as it is; flexible learning situation, diverse students and topics, and at any place or time. Describing the essence of Socrates' method, the core aims of learning and knowledge. The life-long learning, the pure knowledge seeking points to reach the truth, and the purpose of all intellectual questioning are not just to win the opponent but to come to the 
truth. Then, after this aim, all other aims will be fulfilled. If we want to be a political expert and if we answer accurately to all those questions of what the virtue, justice, and wise is, then we will win the opponent too. adult years at the street, answering the life-basic questions such as "What is a virtue", Socrates made a pattern of a basic knowledge a person should have. Answering correctly to these questions, one will prepare him/herself for further life learning. Socrates answer to the question of what the virtue is was that the virtue is knowledge itself, that a person acts his knowledge. So, if he/what is wrong, he/and be virtuous does wrong voluntarily, wrong actions come from the ignorance. When taken appropriately, lifelong learning is not just helpful for an individual but for institutions or society. It is a way to reform and cohesion and it becomes a tool of necessity at this time of rapid changes in different skills and knowledge. What we found more interesting here is that life-long learning enables a person to be a master of his own life and to avoid any kind of subordination. Socrates tried to persuade his audience that the learning is incomplete and that unexamined life is not worth living. Therefore, the process of human development goes on and on until death. It is by this that some authors named Socrates "the prophet of life-long learning". By his insisting on learning throughout the whole life and by helping in that process he deserves this label.

\section{METHODOLOGY}

The writer conducted regular observation to measure the engagement of the students in the reading comprehension course while applying the Socratic study. Observation is often done in research that applies both quantitative and qualitative methods. Research is qualitative when observations are needed to perceive the whole understanding of a particular condition. The result of these observations can be both notes or narratives. The purpose of this observational study was to define the extent to which students are content with the Socratic study, whether or not they involved with it, and most significantly, whether they could transfer information critically, attentively, and open-mindedly through this teaching design. Observation, as noted by McKernan (1991), "is the primary source of educational research" (p. 57). It has two major benefits. First, the use of observation supports the documentation of performance as it happens. Second, it enables the writer to examine what people truly did with what they told they did. During the teaching activity, the writer performed as a camera, listing in a notebook the pros and cons of the scheme. To assign the dialogue worked with their peers with full fluidity, the writer focused on the students' linguistic and non-linguistic performance as well as on their performance in the Socratic study, their responses to the questions and their shaping of other questions. The 
activity, which included 25 students, passed within three steps: the preparation step, in which students study the text and responded comprehension questions; the production step, in which students communicated to each other through questions; and the evaluation step, in which students considered on the whole activity. Students were informed by Paul's (1993) 6-point taxonomy of Socratic questioning: asking and answering clarifying questions, asking questions that examine hypotheses and proof, asking questions concerning other aspects and views, asking questions concerning connections and results, and even asking questions about questions (Knaus, 2006, p. 89). This accommodated them to learn how to pose their questions and how to bypass any likely interference during the Socratic study.

\section{ANALYSIS}

This study is according to the teaching activity of reading comprehension. The writer taught the subject to second-semester students and encouraged them to learn the fundamental skills of reading comprehension, such as seeking for the main idea, paraphrasing, summarizing, synthesizing, and so forth. The 2 hours of the coeducational class involved 25 students. The writer shared reading texts to be prepared for the coming week and assured that a diversity of topics was discussed in those texts. Upon regarding the limited engagement of most students, the writer decided to lengthen the subject by applying the Socratic questioning. The writer worked to intensify students using the Socratic questioning. The goal was to transform students from passive of the reading into active and critical readers. Students were required to read over the text at home, answer comprehension questions, see complicated terms, summarize certain statements, and draw conclusions. At first, students were confusing because they had never been presented to this way of learning before. Nevertheless, they showed a high level of impulse and interest to explore it. Though, the most compelling advantage of the activity was the students' tendency to refuse any answer given by their peers and the former's great intention to think of other probable and useful questions. Another remarkable interest was that the class taught students argumentative skills, attentive listening, and the effect of verbal and nonverbal dialogue. Although not stated as a subject at the higher education, the study, as a one-off instructional strategy accompanied the students in this observational study to think about and reflect on their prior knowledge to review some opinions that had been taken for granted and examine the world from other students' views.

The writer then found that the Socratic questioning led the teaching away from the teacher as an owner of knowledge (the master on the scene) and toward to the students as those who were getting the power to think 
and share knowledge-building in class. Actually, the students attended the study as a double-edged knife. On the one hand, it enabled them to join with the text and indeed go beyond it through significant synergy. On the other hand, it was stimulating for them since the process was constant and the learning situation was hardly tense. Another implication of this observational study is that away from being confrontational with regard to gender, the study was able of sparking a warm conversation and helpful to forming and reshaping students' critical thinking and critical thinking skills.

At the higher education level, they can neither think deep thoughts nor verbalize their ideas orderly because there is no structured higher education subject for that. This pedagogical method was designed to allow engagement to students in a severe and challenging form. The lecturer's part, hence, was solely to present instructions, to motivate students to take part, and then utilize the shot over to them. The Socratic study put students at the center of learning. They were managed to model questions and contribute to the discussions. The underlying idea was that students were responsible for their own learning.

\section{CONCLUSION}

The current of globalization demands students to continually generate knowledge by utilizing rapid technological developments. It can be inferred that most students have the purpose of language learning to develop themselves, continue their studies, and gain knowledge. This requires students to get a better understanding of vocabulary, grammar, and language skills. In integrating critical thinking and foreign language learning, extensive consideration is needed regarding nature, purpose, process, and assessment. Educational practitioners require to further examine the uniqueness of the linguistic context and the cultural context of students before designing the integration implementation of critical thinking in language learning. In studying what distinguishes between the quality of native speaker learners and foreign language students is only in linguistic expression factors while critical thinking skills are not complex (Errihani, 2012). Accordingly, students who have been able to express communicatively in the target language can receive integration-based learning in critical thinking. The use of Socratic questioning method in language learning aimed at promoting students' critical thinking. This method was able to encourage students to optimize their thinking through productive, systematic, directed, and deep questioning so that this is considered to be able to direct the task and be able to clearly explain the root of the problem. This method is able to provide cognitive reinforcement in Bloom's taxonomy. The Socratic questioning is the dominant path to critical thinking. 
Besides presenting students with a field in which to test their selfconfidence as critical readers, thinkers, and speakers, it assists students as an eye-opener for viewing the world from various views. It forces them to think intensely through questioning and intelligent analysis, to listen attentively to others, and to avoid taking their statements at face value. Although the Socratic study could be challenging, constant practice ensures progress. The role of the lecturer should be restricted to that of an observer and facilitator, documenting the students' achievements and failures and thinking on ways to develop the Socratic study in the future. Implementing the Socratic study, in higher education contexts, is profoundly recommended, as it can generate dynamic learners by involving them in the research and evaluation of innovative ideas. Its efficiency, consequently, goes beyond the reading comprehension course to involve other fields.

\section{REFERENCES}

Abelman, R., \& Atkin, D. J. 2011. The Tele viewing Audience: The Art and Science of Watching TV. New York, NY: Peter Lang Publishing.

Anderson\& Krathwohl, D. 2001. A Taxonomy for Learning, Teaching and Assessing: A Revision of Bloom Taxonomy of Educational Objectives. New York: Longman. Benesch, S. 1993. Critical Thinking: A Learning Process for
Democracy. TESOL Quarterly, 31(3), 545-547.

Black, B. 2008. Critical Thinking - A Definition and Taxonomy for Cambridge Assessment: Supporting Validity Arguments about Critical Thinking Assessments Administered by Cambridge Assessment. International Association of Educational Assessment. Cambridge.

Bloom, B. S. 1981. All Our Children Learning: A Primer for Parents, Teachers, and Other Educators. New York:McGraw-Hill.

Boghossian, P. 2012. Socratic Pedagogy: Perplexity, Humiliation, Shame and a Broken Egg. Educational Philosophy and Theory, 44:7, 710-720. 2.

Campbell, Linda, et al., 2004. Teaching and Learning through Multiple Intelligences. Pearson Education Inc. Boston.

Copeland, M. 2005. Socratic Circles: Fostering Critical and Creative Thinking. Portland, ME: Stenhouse Publishers.

Douglas R. O. 2014. The Fact of Ignorance: Revisiting the Socratic Method as a Tool for Teaching Critical Thinking. American Journal of Pharmaceutical Education, Am J Pharm Educ. 78(7) 4.

Emilia, E. 2010. Teaching Writing: Developing Critical Learners. Bandung; Rizqi Press.

Ennis, R.H. 1996. Critical Thinking. New York: Prentice Hall.

Errihani, M. 2012. Critical Thinking and the Language Factor: The 
Case for the English Language Learner. Arab World English Journal, 3: 3, 4-17.

Halpern, D. 1996. Thought and knowledge: An introduction to critical thinking. Mahwah: Lawrence Erlbaum.

Hayat, B \& Yusuf, S. 2010. Benchmark Internasional Mutu Pendidikan. Jakarta: PT Bumi Aksara.

Houghton, R.S., 2004, Communities Resolving Our Problems (CROP): The BasicIdea: Bloom's TaxonomyOverview. Available at http://www.ceap.wcu.edu/houg hton/lea rner/think/blooms Taxonomy.html, Accessed on April 1', 2019.

Indah, R.N. 2012. Communicating Critical Thinking through Bilingual Reflective Writing. Malang: State University of Malang Press, 113-126.

Jacobson, F. F. 1998. Teachers Improving Learning Using Metacognition with SelfMonitoring Learning Strategies. Education, 118(4), 579-589.

Jacobson, F. F., \& Ignacio, E. (1997). Teaching reflection: Information seeking and evaluation in a digital libraryenvironment. Library Trends, 45, 771-802.

Johnson, B. 2003. The Student-Centered Classroom Handbook: A Guide to Implementation. New York, NY: Routledge.

Johnson, Keith. 2001. An Introduction to Foreign Language Learning and Teaching. Pearson Education Ltd, England

Kameo, R.M. 2007. Critical Thinking in The Classroom: Some
Cultural Constraints. English Edu Vol. 7 (1): 1-13.

Knaus, W. J. 2006. Cognitive Behavioral Workbook for Depression: A Stepby-Step Program. Oakland, CA: New Harbinger Publications.

Knezic D., Wubbels T., Elbers E., Hajer M. 2010. The Socratic Dialogue and Teacher Education. Teaching and Teacher Education, 26 1104-1111. 6.

Knox D.K. 1998. Socrates: The First Professor. Innovative Higher Education, 23:2, 115-126. 7.

Lakshmi, G. S. 2012. Techniques of teaching critical thinking. In $\mathrm{Z}$. N. Patil (Ed.), Innovations in English Language Teaching: Voices from the Indian Classroom (pp. 113-133). Hyderabad: Orient Blackswan.

Lam F. 2011. The Socratic Method as an Approach to Learning and Its Benefits. Dietrich College of Humanities and Social Sciences.

Lewis, \& Smith. 2001. Defining Higher Order Thinking. Theory Into Practice, 32(3), 131-137.

Lipman, M. 1991. Thinking in Education. Cambridge: Cambridge University Press.

McKernan, J. 1991. Curriculum Action Research: A Handbook of Methods and Resources for the Reflective Practitioner. London, United Kingdom: Kogan Page.

Norris, S. P., \& Ennis, R. H. 1989. Evaluating Critical Thinking. Pacific Grove, CA: Midwest Publications.

Paul, R. 1993. Critical Thinking: What Every Person Needs to Survive in a Rapidly Changing World. Santa 
Rosa, CA: Foundation for Critical Thinking.

Pithers, R. T. \& Soden, R. 2001. Critical Thinking in Education: a Review. Educational Research, 42: 3, 237-249.

Ramsey et al. 1990. Questioning: An Effective Teaching Method. 00098655. Vol.63, Issue 9 Academic Search Premier.

Reich, R. 2003. The Socratic Method: What it is and How to Use it in the Classroom. Speaking of Teaching, 13, 1-4. Retrieved from https://web.stanford.edu/dept/C TL/Newsletter/ socratic method.pdf

Samanhudi, U \& Sampurna, P. 2010. Researching Students' Critical Thinking in EFL Writing Class ( $A$ Case Study in English Education Department, Untirta). Bandung: UPI

Schiller N. 2008. Finding a Socratic Method for Information Literacy Instruction, College $\mathcal{E}$ Undergraduate Libraries, 15:1-2, 39-56. 13.

Scott, G. A. 2012. Does Socrates Have a Method? Rethinking Elenchus in Plato's Dialogues and Beyond. Philadelphia, PA: The Pennsylvania State University.

Sepriani S. 2010. Teaching Writing through Various Ways to Encourage Police Officer Students' Critical Thinking Development in English as a Foreign Language
Class (An Experience at Indonesian National Police Language Training and Education Center Classroom). Bandung: UPI Siegel, H. 1988. Educating Reason: Rationality, Critical Thinking and Education. New York: Routledge and Metheun.

Soccio, D. J. 2015. Archetypes of Wisdom: An Introduction to Philosophy. Boston, MA: Cengage Learning.

Spencer, S., \& Millson-Martula, C. 2009. Critical Thinking with the Library Program. New York, NY: Routledge.

Tredway, L. 1995. Socratic Seminars: Engaging Students in Intellectual Discourse. Educational Leadership, $53,26-29$.

Vezzosi, M. (n.d.). 2000. Critical Thinking and Reflective Practice: The Role of Information Literacy.

Webster's Encyclopedic Unabridged Dictionary of the English Language. 1989. Portland House, New York

Whitmore, E. 1998. Development of Critical Thinking Skills: An Analysis of Academic Library Experiences and Other Measures. College and Research Libraries, 59(3), 266-273.

Yumarnamto, M \& Widiyanto,Y.M. 2005. Promoting Critical Thinking in EFL Classrooms. Yogyakarta. 